University of Nebraska - Lincoln

DigitalCommons@University of Nebraska - Lincoln

Papers in the Earth and Atmospheric Sciences

Earth and Atmospheric Sciences, Department

2012

\title{
Top-down estimate of dust emissions through integration of MODIS and MISR aerosol retrievals with the GEOS-Chem adjoint model
}

\author{
Jun Wang \\ University of Nebraska-Lincoln, jwang3@unl.edu \\ Xiaoguang $\mathrm{Xu}$ \\ University of Nebraska-Lincoln, xxu@umbc.edu \\ Daven K. Henze \\ University of Colorado \\ Jing Zeng \\ University of Nebraska-Lincoln \\ Qiang Ji \\ University of Maryland \\ See next page for additional authors
}

Follow this and additional works at: https://digitalcommons.unl.edu/geosciencefacpub

Part of the Earth Sciences Commons

Wang, Jun; Xu, Xiaoguang; Henze, Daven K.; Zeng, Jing; Ji, Qiang; Tsay, Si-Chee; and Huang, Jianping, "Top-down estimate of dust emissions through integration of MODIS and MISR aerosol retrievals with the GEOS-Chem adjoint model" (2012). Papers in the Earth and Atmospheric Sciences. 380.

https://digitalcommons.unl.edu/geosciencefacpub/380

This Article is brought to you for free and open access by the Earth and Atmospheric Sciences, Department of at DigitalCommons@University of Nebraska - Lincoln. It has been accepted for inclusion in Papers in the Earth and Atmospheric Sciences by an authorized administrator of DigitalCommons@University of Nebraska - Lincoln. 


\section{Authors}

Jun Wang, Xiaoguang Xu, Daven K. Henze, Jing Zeng, Qiang Ji, Si-Chee Tsay, and Jianping Huang 


\title{
Top-down estimate of dust emissions through integration of MODIS and MISR aerosol retrievals with the GEOS-Chem adjoint model
}

\author{
Jun Wang, ${ }^{1}$ Xiaoguang Xu, ${ }^{1}$ Daven K. Henze, ${ }^{2}$ Jing Zeng, ${ }^{1}$ Qiang Ji, ${ }^{3,4}$ Si-Chee Tsay, ${ }^{4}$ \\ and Jianping Huang ${ }^{5}$
}

Received 26 January 2012; revised 13 March 2012; accepted 21 March 2012; published 20 April 2012.

[1] Predicting the influences of dust on atmospheric composition, climate, and human health requires accurate knowledge of dust emissions, but large uncertainties persist in quantifying mineral sources. This study presents a new method for combined use of satellite-measured radiances and inverse modeling to spatially constrain the amount and location of dust emissions. The technique is illustrated with a case study in May 2008; the dust emissions in Taklimakan and Gobi deserts are spatially optimized using the GEOSChem chemical transport model and its adjoint constrained by aerosol optical depth (AOD) that are derived over the downwind dark-surface region in China from MODIS (Moderate Resolution Imaging Spectroradiometer) reflectance with the aerosol single scattering properties consistent with GEOS-chem. The adjoint inverse modeling yields an overall $51 \%$ decrease in prior dust emissions estimated by GEOS-Chem over the Taklimakan-Gobi area, with more significant reductions south of the Gobi Desert. The model simulation with optimized dust emissions shows much better agreement with independent observations from MISR (Multi-angle Imaging SpectroRadiometer) AOD and MODIS Deep Blue AOD over the dust source region and surface $\mathrm{PM}_{10}$ concentrations. The technique of this study can be applied to global multi-sensor remote sensing data for constraining dust emissions at various temporal and spatial scales, and hence improving the quantification of dust effects on climate, air quality, and human health. Citation: Wang, J., X. Xu, D. K. Henze, J. Zeng, Q. Ji, S.-C. Tsay, and J. Huang (2012), Top-down estimate of dust emissions through integration of MODIS and MISR aerosol retrievals with the GEOS-Chem adjoint model, Geophys. Res. Lett., 39, L08802, doi:10.1029/ 2012GL051136.

\section{Introduction}

[2] Mineral dust aerosol has important impacts on climate change, air quality, and ocean biological systems [Intergovernmental Panel on Climate Change, 2007]. How-

\footnotetext{
${ }^{1}$ Department of Earth and Atmospheric Sciences, University of Nebraska-Lincoln, Lincoln, Nebraska, USA.

${ }^{2}$ Department of Mechanical Engineering, University of Colorado at Boulder, Boulder, Colorado, USA.

${ }^{3}$ Earth System Science Interdisciplinary Center, University of Maryland, College Park, Maryland, USA.

${ }^{4}$ NASA Goddard Space Flight Center, Greenbelt, Maryland, USA. China.

${ }^{5}$ College of Atmospheric Sciences, Lanzhou University, Lanzhou,

Copyright 2012 by the American Geophysical Union. 0094-8276/12/2012GL051136
}

ever, significant uncertainties exist in mineral dust sources due to poor understanding of dust uplifting mechanisms and lack of in situ measurements over the desert region. Quantitative description of processes such as sandblasting and saltation bombardment in a chemistry transport model (CTM) requires knowledge of many parameters that can not be accurately characterized spatially and temporally, including surface wind speed, soil moisture, soil texture, surface cover type, and topography [Ginoux et al., 2001; Tegen et al., 2002; Zender et al., 2003]. Not surprisingly, recent estimates in CTMs span from a few hundreds to over $4000 \mathrm{Tg}$ for annual global dust emissions [Huneeus et al., 2011] and vary by several orders of magnitude for emissions of dust events at regional scales [Uno et al., 2006]. An observation-based approach, therefore, is needed to reduce these large uncertainties in estimates of dust emissions.

[3] In the last decade, in parallel with the advancement of in situ and remote sensing observation of dust aerosol, techniques have been developed to use these observations as constraints on dust sources. Cakmur et al. [2006] optimized dust emissions in a global model utilizing surface measurements of aerosol optical depth (AOD) and dust concentrations, providing an estimate of $1600-2500 \mathrm{Tg} \mathrm{yr}^{-1}$. Dubovik et al. [2008] developed the GOCART adjoint modeling system for constraining global emissions of both fine and coarse mode dust from MODIS-based fine and coarse mode AOD, respectively. At a regional scale, Ku and Park [2011] constrained soil emissions over East Asia by minimizing the difference between modeled and measured daily surface mass concentration of particulate matter less than $10 \mu \mathrm{m}$ in aerodynamic diameter $\left(\mathrm{PM}_{10}\right)$ in the downwind region through Bayesian least-squares analysis. Yumimoto et al. [2007] used a four-dimensional variational (4D-Var) system to optimize Asian dust emissions with constraints from ground-based lidar observations.

[4] However, in the aforementioned studies, only a few independent observations far from the source region are used to validate estimates of dust emissions because groundbased observations of dust particles (particularly over the desert region) are sparse. Furthermore, while satellite AOD is a better constraint than surface measurements for estimating dust emissions as AOD represents the vertical loading of aerosols and thus the optimization of emission will be less sensitive to uncertainties in the simulated aerosol vertical profile, the discrepancy of aerosol optical properties between model and satellite can pose a challenge to attributing the differences between satellite and modeled dust AOD to errors of dust emissions alone [Drury et al., 2008; Wang et al., 2010]. 



Figure 1. (a) True color image from MODIS/Aqua on 27 May 2008. The region within the rectangle of dashed line is the downwind plume region where the observational data are used. The region within the rectangle of dotted line is used for validation. (b) The prior mineral dust emission for the period of 25-28 May 2008. (c) Same as Figure 1b but for optimized dust emission. (d) The ratio of the optimized to prior dust emission. (e) MODIS AOD at $0.67 \mu \mathrm{m}$ aggregated to GEOS grid box and averaged for the period of 25-28 May 2008, which served as observational constraint for the adjoint inverse modeling of dust emission. (f) GEOS-chem total AOD at $0.67 \mu \mathrm{m}$ simulated with prior dust emission averaged over satellite overpass time period (see text for details). (g) Same as Figure 1f but for the AOD simulated with optimized emission. (h) Ratio between Figures $1 \mathrm{f}$ and $1 \mathrm{~g}$.

[5] This study presents a new method to constrain dust emissions through integrated use of a chemical transport model (GEOS-Chem [Bey et al., 2001]) and its adjoint [Henze et al., 2007] with satellite-measured radiances. Although the adjoint optimization technique we use is similar to that of Dubovik et al. [2008] and Yumimoto et al. [2007], our study differs from the past studies in that: (a) the aerosol single scattering properties between GEOSChem and the satellite retrieval algorithms are consistent, and hence in essence it is the satellite-measured radiances that are used as constraints; (b) because of (a), the difference between satellite-based and model simulated AOD can, to first order, be attributed to model biases in the columnar loading of aerosols that is well suited to constrain the emissions; (c) optimization of dust emissions are conducted for every grid box as a function of time (e.g., on the daily basis); (d) the posterior dust emissions are evaluated spatially and temporally through comprehensive use of independent aerosol measurements from multiple satellite sensors and a field campaign. Specifically, the method is illustrated with a case study over East Asia for a dust event in May 2008 (Figure 1a) during a joint China-U.S. dust field experiment [Huang et al., 2010]. The dust emissions in Taklimakan (hereafter TAK) and Gobi deserts are optimized daily using AOD retrieved from MODIS radiance [Wang et al., 2010] over the dark-surface region in China located downwind of the source region. In contrast, independent data sets are used for evaluating the optimization results over the dust source region, including MISR level-2 AOD [Kahn et al.,
2005], the MODIS level-2 bright-surface Deep Blue AOD [Hsu et al., 2006], sunphotometer-measured AOD, and ground-based measurements of $\mathrm{PM}_{10}$ from the field campaign during 2008 China-U.S. joint dust field experiments over Zhangye $\left(39.08^{\circ} \mathrm{N}, 100.3^{\circ} \mathrm{E}\right.$, and denoted by green triangle in Figure 1a) [Huang et al., 2010].

\section{GEOS-Chem Model and Its Constraints From MODIS}

[6] GEOS-Chem [Bey et al., 2001] is a global threedimensional tropospheric chemical transport model driven by assimilated meteorological observations from the Goddard Earth Observing System (GEOS) of the NASA Global Modeling and Assimilation Office (GMAO). This model simulates the mass concentration of mineral dust in 4 size bins, together with sulfate, nitrate, ammonium, black and organic carbon in both hydrophilic and hydrophobic modes, and sea salt aerosols in both accumulation and coarse modes. The mineral dust entrainment and deposition (DEAD) scheme [Fairlie et al., 2007; Zender et al., 2003], combined with the GOCART topographic source function [Ginoux et al., 2001], is used in this study to calculate the first guess, or prior dust emission flux, as a function of wind friction velocity, soil moisture and soil particle size.

[7] Dust emissions are constrained using MODIS AOD over the downwind dark-surface region (within the red dashed rectangle in Figure 1a) retrieved from an improved algorithm developed by Wang et al. [2010]. Key to this 
retrieval algorithm are: (a) a database of time-dependent surface $0.65 \mu \mathrm{m}$ and $2.1 \mu \mathrm{m}$ reflectance ratios that are derived from samples of the MODIS dark-pixel reflectance data in low AOD conditions (e.g., "dynamic lower envelope" approach) for each GEOS-Chem model gridbox, and (b) an assumption that the simulated GEOS-Chem aerosol is unbiased in composition (but possibly largely biased in total mass), enabling use of the GEOS-Chem aerosol single scattering properties in the retrieval including the wavelengthdependence relationship needed for estimating AOD at $2.1 \mu \mathrm{m}$ from the AOD at $0.67 \mu \mathrm{m}$. With (a), (b), and a linearized radiative transfer model that computes the top-ofatmosphere radiance and the sensitivity of radiance to the column AOD, Wang et al. [2010] is able to retrieve two unknowns (AOD at $0.67 \mu \mathrm{m}$ and surface reflectance at $2.13 \mu \mathrm{m}$ ) from two known quantities (MODIS reflectances at 0.67 and $2.1 \mu \mathrm{m})$.

[8] Since the aerosol single scattering properties are consistent between the retrieval algorithm and GEOS-Chem, the retrieval essentially uses MODIS radiances (in the form of AOD) to scale the GEOS-Chem aerosol mass loading in each model grid column while keeping the aerosol composition and aerosol vertical profile shape intact. Hence, this scale factor or the ratio of AOD between MODIS and GEOS-Chem (simulated with prior emission) is also the dust AOD scale factor that is needed for GEOS-chem simulated radiances to be consistent with MODIS radiances. Consequently, in cloud-free conditions, this (dust) AOD scale factor, twice per day respectively obtained from MODIS/ Terra and MODIS/Aqua retrieval, is used as a constraint for the GEOS-chem adjoint modeling. To ensure that the constraint pertains to dust aerosols, only those (dust) AOD scale factors along the downwind dust transport path (e.g., retrieved dust AOD greater than 0.2) are used.

[9] GEOS-chem simulated aerosol composition over Asia is shown by few studies to have low bias in black carbon (BC), and equivalent or larger underestimation of organic carbon (OC) mass and overestimation of sulfate aerosol mass [Heald et al., 2005; Fu et al., 2012], which suggests that the mass fraction of highly absorbing (BC) and highly scattering (OC and sulfate) fine mode aerosols may have far less biases (as compared to the relative bias in OC mass only). Consequently, no significant biases are expected for (a) the GEOS-chem simulated fraction of coarse mode (dust) aerosol mass, and (b) the GEOS-chem simulated aerosol single scattering albedo. While (b) is important to ensure an unbiased retrieval of AOD, (a) supports that the GEOS-chem simulated dust AOD fraction is likely unbiased, both of which support the use of (dust) AOD scale factor derived from MODIS for constraining the dust emission. Admittedly, any model bias in modeled dust AOT fraction can lead to a corresponding bias (of the same sign) in the adjoint modeling results for dust emission. Further quantification of such bias requires a separate future study owing to the lack of aerosol composition data in China.

\section{Implementation of GEOS-Chem Dust Adjoint Modeling}

[10] The adjoint of the GEOS-Chem model was developed specifically for inverse modeling of aerosol (or their precursors) and gas emissions [Henze et al., 2007]. The advantage of the adjoint approach is its ability to efficiently calculate model sensitivities with respect to large sets of model parameters, such as aerosol emissions at each grid box, which can serve as the gradients needed for inverse modeling of aerosol emissions. Here we implemented for the first time the adjoint of the GEOS-Chem dust simulation. Dust emissions are adjusted using a vector of control parameters $\boldsymbol{\sigma}$ that are the logarithm of emission scaling factors for dust emissions: $\boldsymbol{\sigma}=\ln \left(\mathbf{F} / \mathbf{F}_{a}\right)$, where $\mathbf{F}$ and $\mathbf{F}_{\mathbf{a}}$ are posterior and prior dust emissions vectors, respectively. The model response function, or the cost function, $J$, for the logarithmic dust emission scaling factor $\sigma$, is formulated as:

$$
\begin{aligned}
J(\boldsymbol{\sigma})= & \frac{1}{2} \sum_{c \in \Omega}\left[H \mathbf{c}(\boldsymbol{\sigma})-\mathbf{c}_{o b s}\right]^{T} \mathbf{S}_{o b s}^{-1}\left[H \mathbf{c}(\boldsymbol{\sigma})-\mathbf{c}_{o b s}\right] \\
& +\gamma \frac{1}{2}\left[\boldsymbol{\sigma}-\boldsymbol{\sigma}_{a}\right]^{T} \mathbf{S}_{a}^{-1}\left[\boldsymbol{\sigma}-\boldsymbol{\sigma}_{a}\right]
\end{aligned}
$$

where $\mathbf{c}$ is the vector of model dust concentration (mixing ratio in the units of ppbv), $H$ is the observation operator that transforms $\mathbf{c}$ to four-dimensional spatial and temporal observation space $\Omega, \mathbf{c}_{\mathrm{obs}}$ is the vector of observed dust concentration described in Section $2, \mathbf{S}_{\text {obs }}$ is the observation error covariance matrix for dust concentration, $\gamma$ is a regulization parameter, $\sigma_{\mathrm{a}}$ is a vector of prior control parameters, and $\mathbf{S}_{\mathrm{a}}$ is the error covariance matrix of $\boldsymbol{\sigma}_{\mathrm{a}}$. The adjoint optimization seeks to optimize $\boldsymbol{\sigma}$ by minimizing the cost function $J$ through computing its gradient with respect to $\sigma$ (i.e., $\nabla_{\sigma} J(\sigma)$ ) iteratively in combination with the quasi-Newton L-BFGS-B algorithm [Byrd et al., 1995; Henze et al., 2007].

[11] Assumptions regarding the error in the observations and prior sources have important impacts on the optimization results. Based on assessments of the retrieved AOD (from MODIS) by Wang et al. [2010], we set the relative error for $\boldsymbol{c}_{\mathrm{obs}}$ as $20 \%$ and only consider model grid columns where dust mixing ratios are $0.2 \mathrm{ppbv}$ and above because we are only interested in optimizing dust emissions. Similar to previous studies [Dubovik et al., 2008], $\mathbf{S}_{\mathrm{obs}}$ is assumed to have zero off-diagonal elements, and its diagonal values are the variance of each observation. To reflect the possibly large dust emission uncertainties in the model [Huneeus et al., 2011], $\mathbf{S}_{\mathrm{a}}$ is set to be diagonal with error of $200 \%$. Lacking information to fully construct a physically representative $\mathbf{S}_{\mathrm{a}}$, a regularization parameter (here $\gamma=1000$ ) is introduced to balance the contribution of model error and source error in the cost function, with a value selected using the "L-curve" technique [Hansen, 1998]. As a case study to illustrate the inversion of dust emissions, we first spin up the forward model simulation from 1 January 2008, and then run the forward and adjoint model iteratively for the period of 20-31 May 2008 during which dust events occurred (2528 May). The inverse modeling is conducted 5 days before the dust event to minimize the influence of initial conditions.

\section{Results}

[12] Figures 1b-1d show the geographic distribution of the prior and posterior dust emissions, as well as the ratio of posterior to prior dust emissions during 25-28 May 2008. The posterior result in Figure 1c is obtained when the cost function is sufficiently reduced (by $\sim 60 \%$ after 8 iterations). As shown in Figure 1b, the DEAD (or prior) dust mobilization scheme captures the overall distribution for the dust 

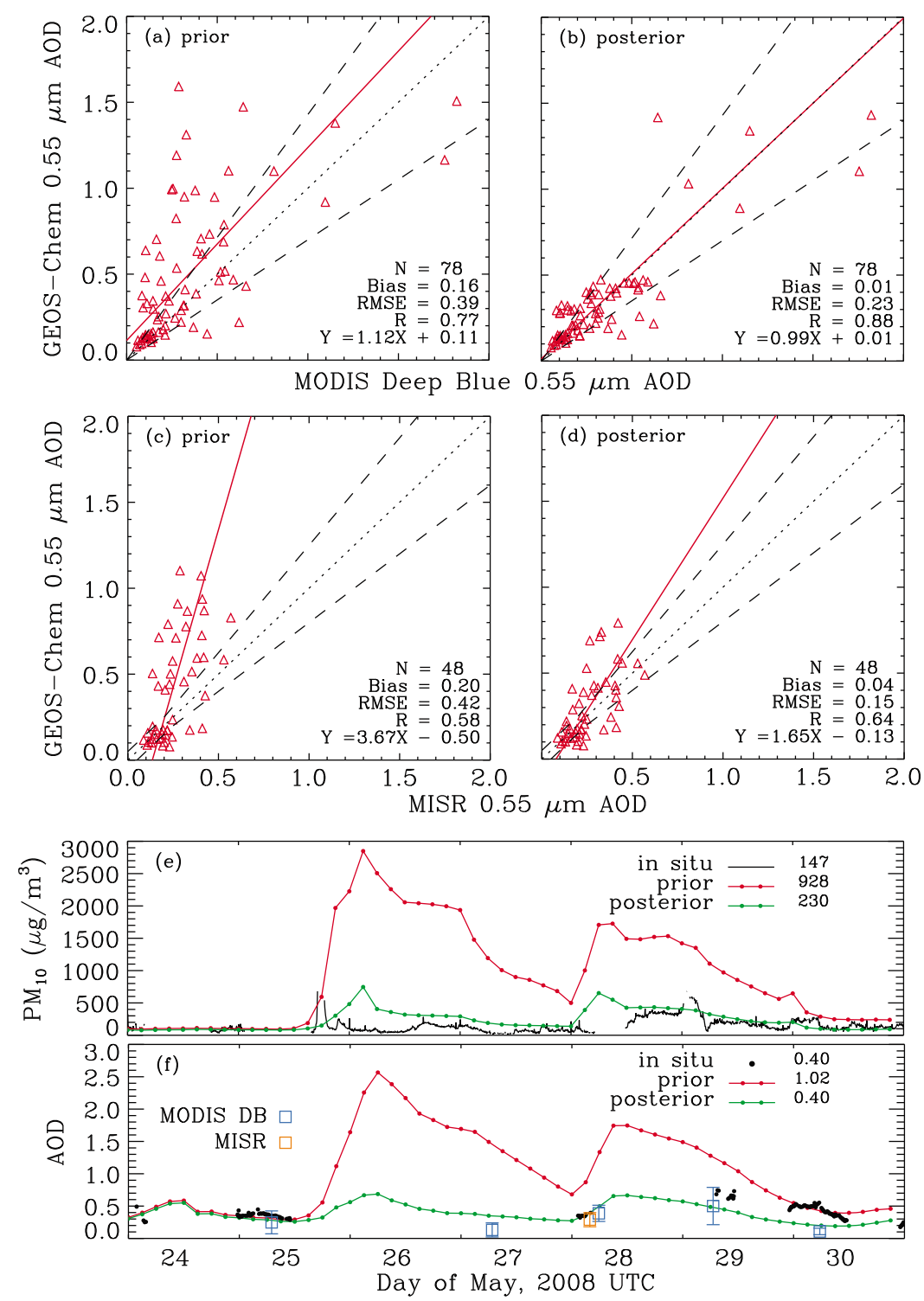

Figure 2. (a) Scatter plot of GEOS-Chem AOD simulated with prior emission and the MODIS Deep Blue (DB) AOD over the dust source region for the period of 25-28 May 2008. The number of samples $(\mathrm{N})$, bias, correlation (R), root mean square error (RMSE), and linear equation from reduced-major-axis regression are also shown. (b-d) Similar to Figure 2a but for the comparison of GEOS-Chem posterior (e.g., optimized) vs. MODIS Deep Blue AOD, GEOS-Chem prior vs. MISR AOD, and GEOS-Chem optimized vs. MISR AOD, respectively. In Figures 2a-2d, dotted and solid lines respectively show one-to-one fit and best linear fit between variables in $\mathrm{x}$ and $\mathrm{y}$ axis, while dashed line show the expected uncertainty in satellite-based AOD (i.e., $\pm 20 \%$ for both MSIR MODIS Deep Blue), (e) time serial plot of GEOS-Chem simulated surface $\mathrm{PM}_{10}$ concentration by prior (red line) and posterior (green) emission compared with the in situ measured $\mathrm{PM}_{10}$ (black) over Zhangye station; also shown (on the upper right corner) are respectively the averaged value for these quantities over the same period. (f) Same as Figure 2e but for AOD time series with additional overlay of MODIS Deep Blue and MISR AODs (denoted respectively as blue and orange square).

sources that are primarily located in the Takalaman desert and the Gobi deserts. While the prior and the posterior show consistent spatial patterns of dust emission over the Takalaman region, the prior generally overestimates emissions by a factor of 2-3 over the Gobi desert. Overall, the optimization yields a $51 \%$ decrease in prior emissions, changing the total emission from $9.36 \mathrm{Tg}$ to $4.55 \mathrm{Tg}$. The convergence between model and observation can be verified in that the model is in much better agreement with MODIS AOD (Figure 1e) after optimization in comparison with before optimization (Figure 1f). As expected, the adjustment of dust emissions in the optimization is consistent with the changes in GEOS-Chem AOD before and after optimization (Figure 1h).

[13] To validate the results of the inversion, we focus on the dust simulation over and near the source region where the dust has only been transported a short distance with minimal influence of precipitation and anthropogenic aerosol. Figures $2 \mathrm{a}$ and $2 \mathrm{~d}$ show the comparison of the GEOSChem AOD with independent measurements before and after optimization. The model AOD values in Figure 2 are 6hour averages during 1:30-7:30 UTC that span the MODIS/ 
Aqua and MISR/Terra overpass times, and the distribution of those AODs are shown in Figure S1 in the auxiliary material. ${ }^{1}$ When taking MODIS Deep Blue retrievals of AOD as reference, AOD values simulated from GEOSChem with posterior emissions have a better correlation $(\mathrm{R}=0.88)$, smaller bias $(0.01)$, and smaller root mean squared error $(\mathrm{RMSE}=0.23)$ than the counterparts using prior emission $(\mathrm{R}=0.77$, bias $=0.16$, $\mathrm{RMSE}=0.39)$, which quantifies the improvements in the dust simulation with the optimized dust emission. Overall, the optimized GEOSChem AOD over $80 \%$ of grid boxes are within expected accuracy $(100 \pm 30 \%)$ of MODIS Deep Blue retrievals. Similar improvements are also found in the comparison of the model AOD to MISR AOD in Figures $2 \mathrm{c}$ and 2d, where bias and RMSE are reduced from 0.20 and 0.42 to 0.04 and 0.15 , respectively.

[14] The improvement of the model dust emission is further reflected in the comparison of simulated near-surface dust concentration with ground-based observations. When compared to the ground measurements of $\mathrm{PM}_{10}$ concentration and AOD at Zhangye for the dusty time period, the modeled counterparts before the optimization of dust emission correspondingly show a large positive bias or overestimates by a factor of up to 5 (Figure 2e). This bias is significantly reduced in the simulation with posterior emissions. Moreover, the comparison of time series of AOD also shows that the modeled AOD after optimization has a much better agreement with MODIS Deep Blue and MISR retrievals (Figure 2f).

\section{Summary and Discussions}

[15] This study presents, for the first time, the integration of MODIS and MSIR data with the adjoint capacity for constraining dust emissions in the GEOS-Chem adjoint framework and conducts a case study that optimizes dust emissions in Taklimakan and Gobi deserts over East Asia for a dust event in May 2008. The model simulation with optimized dust emissions shows much better agreement with independent satellite and ground-based observations in the dust source region. This encouraging result confirms that using satellite observation combined with inverse modeling is an effective method for reducing the large uncertainties in estimates of dust emissions.

[16] Indeed, estimates of dust radiative effect and forcing have been largely based upon modeling studies thus far [Forster et al., 2007]. However, the semi-arid and arid areas, in global averages, are expanding with time due to global warming, and hence, timely updates of dust source information, at finer spatial and temporal scales, is not only highly needed but also an outstanding challenge for chemistry transport models [Denman et al., 2007]. Taking advantage of (i) adjoint modeling capabilities that can efficiently calculate the model spatial and temporal sensitivities of AOD with respect to model input parameters, and (ii) the high spatial and temporal coverage of satellite remote sensing of aerosols, the method developed in this study can be applied to over ten years of MISR and MODIS observations (with an estimated computational time of $\sim 6$ months if using a Linux cluster of $323.0 \mathrm{GHz} \mathrm{CPUs}$ ), and hence has the

\footnotetext{
${ }^{1}$ Auxiliary materials are available in the HTML. doi:10.1029/ 2012GL051136.
}

potential to improve and resolve the estimate of dust emissions at various spatial and temporal scales. Extension of the adjoint sensitivity tool developed here to examine the impact of specific mobilization parameters (such as the velocity threshold needed for dust mobilization) may advance the use satellite data to improve dust emission parameterization schemes. Consequently, such satellite-based constraints could improve our modeling of the dust radiative forcing, could potentially illuminate anthropogenic components of dust sources and loadings, currently estimated at $0-20 \%$ though values as large as 50\% have been postulated [Forster et al., 2007], and could help refine understandings of longerterm feedbacks between land-use, climate and dust aerosol.

[17] The results of this study are based upon analysis of a single dust event, and are therefore subject to model uncertainties regarding the relative bias in model simulated aerosol composition and the aerosol size distribution, and to a lesser extent (because we use columnar AOD as a model constraint and select the days with little precipitation), the model errors in aerosol vertical profile and precipitation. While the use of model-simulated single scattering properties in the retrieval of AOD from satellites strengthens the direct use of satellite radiances to constrain modeled AOD and aerosol emissions, satellite AOD products, for computational expedience, may still be assimilated in regions where aerosol properties are dominated by one aerosol species (such as dust or smoke) and thus may be represented in stand-alone retrieval algorithms. However, in the long term, the use of satellite radiances to improve the aerosol model is the ultimate goal; this requires dedicated field experiments and in situ observations to provide evaluation of model improvements, as well as satellite missions that are dedicated to measurements containing information content beyond AOD (such as those with multi-angle multi-polarization to retrieve aerosol size and/or refractive indices) [Kahn, 2012].

[18] Nevertheless, as shown here with use of the satellite radiances, our finding of an overall $50 \%$ overestimation of dust emission in the model is consistent with $K u$ and Park [2011] (although there are some geographical differences due to the use of different versions of GEOS meteorology and thus different prior emissions), likely reflecting a systematic bias in GEOS-Chem, and hence bearing important implications. A simple extrapolation of our results, using 1D radiative transfer calculations with dust single scattering albedo of 0.96 in the mid-visible, implies a $\sim 20 \%$ decrease of the dust direct radiative effect in annual and global average. Further, if natural sources have been overestimated, then the anthropogenic fraction of the dust radiative effect $(-0.5$ to $+0.1 \mathrm{Wm}^{-2}$ [Forster et al., 2007]) may have effectively been substantially underestimated.

[19] Acknowledgments. This study is supported by the NASA Radiation Sciences Program managed by Dr. Hal B. Maring, NASA Glory project (NNX11AB91G), and NASA Atmospheric Chemistry Modeling and Analysis Program (NNX10AG60G) managed by Dr. Richard S. Eckman.

[20] The Editor thanks two anonymous reviewers for assisting with the evaluation of this paper.

\section{References}

Bey, I., D. J. Jacob, R. M. Yantosca, J. A. Logan, B. D. Field, A. M. Fiore Q. Li, H. Y. Liu, L. J. Mickley, and M. G. Schultz (2001), Global modeling of tropospheric chemistry with assimilated meteorology: Model description and evaluation, J. Geophys. Res., 106(D19), 23,073-23,095, doi:10.1029/2001JD000807. 
Byrd, R. H., P. Lu, J. Nocedal, and C. Zhu (1995), A limited memory algorithm for bound constrained optimization, SIAM J. Sci. Comput., 16 1190-1208, doi:10.1137/0916069.

Cakmur, R. V., R. L. Miller, J. Perlwitz, I. V. Geogdzhayev, P. Ginoux, D. Koch, K. E. Kohfeld, I. Tegen, and C. S. Zender (2006), Constraining the magnitude of the global dust cycle by minimizing the difference between a model and observations, J. Geophys. Res., 111, D06207, doi:10.1029/2005JD005791.

Denman, K. L. et al. (2007), Couplings between changes in the climate system and biogeochemistry, in Climate Change 2007: The Physical Science Basis. Contribution of Working Group I to the Fourth Assessment Report of the Intergovernmental Panel on Climate Change, edited by S. Solomon et al., pp. 499-587, Cambridge Univ. Press, Cambridge, U. K.

Drury, E., D. J. Jacob, J. Wang, R. J. D. Spurr, and K. Chance (2008), Improved algorithm for MODIS satellite retrievals of aerosol optical depths over western North America, J. Geophys. Res., 113, D16204, doi:10.1029/2007JD009573.

Dubovik, O., et al. (2008), Retrieving global aerosol sources from satellites using inverse modeling, Atmos. Chem. Phys., 8(2), 209-250, doi:10.5194/ acp-8-209-2008.

Fairlie, D. T., D. J. Jacob, and R. J. Park (2007), The impact of transpacific transport of mineral dust in the United States, Atmos. Environ., 41(6), 1251-1266, doi:10.1016/j.atmosenv.2006.09.048.

Forster, P. et al. (2007), Changes in atmospheric constituents and in radiative forcing, in Climate Change 2007: The Physical Science Basis. Contribution of Working Group I to the Fourth Assessment Report of the Intergovernmental Panel on Climate Change, edited by S. Solomon et al., pp. 129-234, Cambridge Univ. Press, Cambridge, U. K.

Fu, T.-M., et al. (2012), Carbonaceous aerosols in China: Top-down constraints on primary sources and estimation of secondary contribution, Atmos. Chem. Phys., 12, 2725-2746, doi:10.5194/acp-12-2725-2012.

Ginoux, P., M. Chin, I. Tegen, J. M. Prospero, B. Holben, O. Dubovik, and S.-J. Lin (2001), Sources and distributions of dust aerosols simulated with the GOCART model, J. Geophys. Res., 106(D17), 20,255-20,273, doi:10.1029/2000JD000053.

Hansen, P. C. (1998), Rank-Deficient and Discrete Ill-Posed Problems: Numerical Aspects of Linear Inversion, Soc. for Ind. and Appl. Math., Philadelphia, Pa., doi:10.1137/1.9780898719697.

Heald, C. L., D. J. Jacob, R. J. Park, L. M. Russell, B. J. Huebert, J. H. Seinfeld, H. Liao, and R. J. Weber (2005), A large organic aerosol source in the free troposphere missing from current models, Geophys. Res. Lett., 32, L18809, doi:10.1029/2005GL023831.

Henze, D. K., A. Hakami, and J. H. Seinfeld (2007), Development of the adjoint of GEOS-Chem, Atmos. Chem. Phys., 7(9), 2413-2433, doi:10.5194/acp-7-2413-2007.

Hsu, N. C., et al. (2006), Deep Blue retrievals of Asian aerosol properties during ACE-Asia, IEEE Trans. Geosci. Remote Sens., 44(11), 3180-3195, doi:10.1109/TGRS.2006.879540.

Huang, Z., J. Huang, J. Bi, G. Wang, W. Wang, Q. Fu, Z. Li, S.-C. Tsay, and J. Shi (2010), Dust aerosol vertical structure measurements using three MPL lidars during 2008 China-U.S. joint dust field experiment, J. Geophys. Res., 115, D00K15, doi:10.1029/2009JD013273.

Huneeus, N., et al. (2011), Global dust model intercomparison in AeroCom phase I, Atmos. Chem. Phys., 11(15), 7781-7816, doi:10.5194/acp-117781-2011.

Intergovernmental Panel on Climate Change (2007), Climate Change 2007: The Physical Science Basis. Contribution of Working Group I to the Fourth Assessment. Report of the Intergovernmental Panel on Climate Change, edited by S. Solomon et al., 996 pp., Cambridge Univ. Press, Cambridge, U. K

Kahn, R. A. (2012), Reducing the uncertainties in direct aerosol radiative forcing, Surv. Geophys., doi:10.1007/s10712-011-9153-z, in press.

Kahn, R. A., B. J. Gaitley, J. V. Martonchik, D. J. Diner, K. A. Crean, and B. Holben (2005), Multiangle Imaging Spectroradiometer (MISR) global aerosol optical depth validation based on 2 years of coincident Aerosol Robotic Network (AERONET) observations, J. Geophys. Res., 110, D10S04, doi:10.1029/2004JD004706.

$\mathrm{Ku}, \mathrm{B}$., and R. J. Park (2011), Inverse modeling analysis of soil dust sources over East Asia, Atmos. Environ., 45(32), 5903-5912, doi:10.1016/j. atmosenv.2011.06.078.

Tegen, I., S. P. Harrison, K. Kohfeld, I. C. Prentice, M. Coe, and M. Heimann (2002), Impact of vegetation and preferential source areas on global dust aerosol: Results from a model study, J. Geophys. Res. 107(D21), 4576, doi:10.1029/2001JD000963.

Uno, I., et al. (2006), Dust model intercomparison (DMIP) study over Asia: Overview, J. Geophys. Res., 111, D12213, doi:10.1029/2005JD006575.

Wang, J., et al. (2010), Improved algorithm for MODIS satellite retrievals of aerosol optical thickness over land in dusty atmosphere: Implications for air quality monitoring in China, Remote Sens. Environ., 114(11), 2575-2583, doi:10.1016/j.rse.2010.05.034.

Yumimoto, K., I. Uno, N. Sugimoto, A. Shimizu, and S. Satake (2007), Adjoint inverse modeling of dust emission and transport over East Asia, Geophys. Res. Lett., 34, L08806, doi:10.1029/2006GL028551.

Zender, C. S., H. Bian, and D. Newman (2003), Mineral Dust Entrainment and Deposition (DEAD) model: Description and 1990s dust climatology, J. Geophys. Res., 108(D14), 4416, doi:10.1029/2002JD002775.

D. K. Henze, Department of Mechanical Engineering, University of Colorado at Boulder, 427 UCB, Boulder, CO 80309, USA.

J. Huang, College of Atmospheric Sciences, Lanzhou University, Lanzhou 730000, China.

Q. Ji, Earth System Science Interdisciplinary Center, University of Maryland, 5825 University Research Ct., Ste. 4001, College Park, MD 20742, USA.

S.-C. Tsay, NASA Goddard Space Flight Center, Code 613, Greenbelt, MD 20771, USA.

J. Wang, X. Xu, and J. Zeng, Department of Earth and Atmospheric Sciences, University of Nebraska-Lincoln, 303 Bessey Hall, Lincoln, NE 68588, USA. (jwang7@unl.edu) 
Auxiliary Material for:

\section{Top-down estimate of dust emissions through integration of MODIS and MISR aerosol retrievals with the GEOS-Chem adjoint model}

Jun Wang and Xiaoguang Xu

Department of Earth and Atmospheric Sciences, University of Nebraska, Lincoln, Nebraska, USA

Daven K. Henze

Department of Mechanical Engineering, University of Colorado at Boulder,

Boulder, Colorado, USA

Jing Zeng

Department of Earth and Atmospheric Sciences, University of Nebraska, Lincoln, Nebraska, USA

Qiang Ji

Earth System Science Interdisciplinary Center, University of Maryland, College Park, Maryland, USA

NASA Goddard Space Flight Center,

Greenbelt, Maryland, USA

Si-Chee Tsay

NASA Goddard Space Flight Center,

Greenbelt, Maryland, USA

Jianping Huang

College of Atmospheric Sciences, Lanzhou University,

Lanzhou, China

Wang, J., X. Xu, D. K. Henze, J. Zeng, Q. Ji, S.-C. Tsay, and J. Huang (2012), Top-down estimate of dust emissions through integration of MODIS and MISR aerosol retrievals with the GEOS-Chem adjoint model, Geophys. Res. Lett., 39, L08802, doi:10.1029/2012GL051136. 


\section{Introduction}

The auxiliary material here is one figure describing the geographical distribution of MODIS Deep Blue (DB) and MISR Aerosol Optical Depth (AOD) at 0.55 micrometer.

Figure S1. The top panels show MODIS DB and MISR AOD at 0.55 um in the dust source regions for the period 25-28 May 2008. Middle panels show GEOS-Chem column 0.55 um AOD with prior dust emissions sampled coincidently with MODIS DB (left) and MISR (right). The bottom panels are same as the middle ones but using optimized dust emissions.
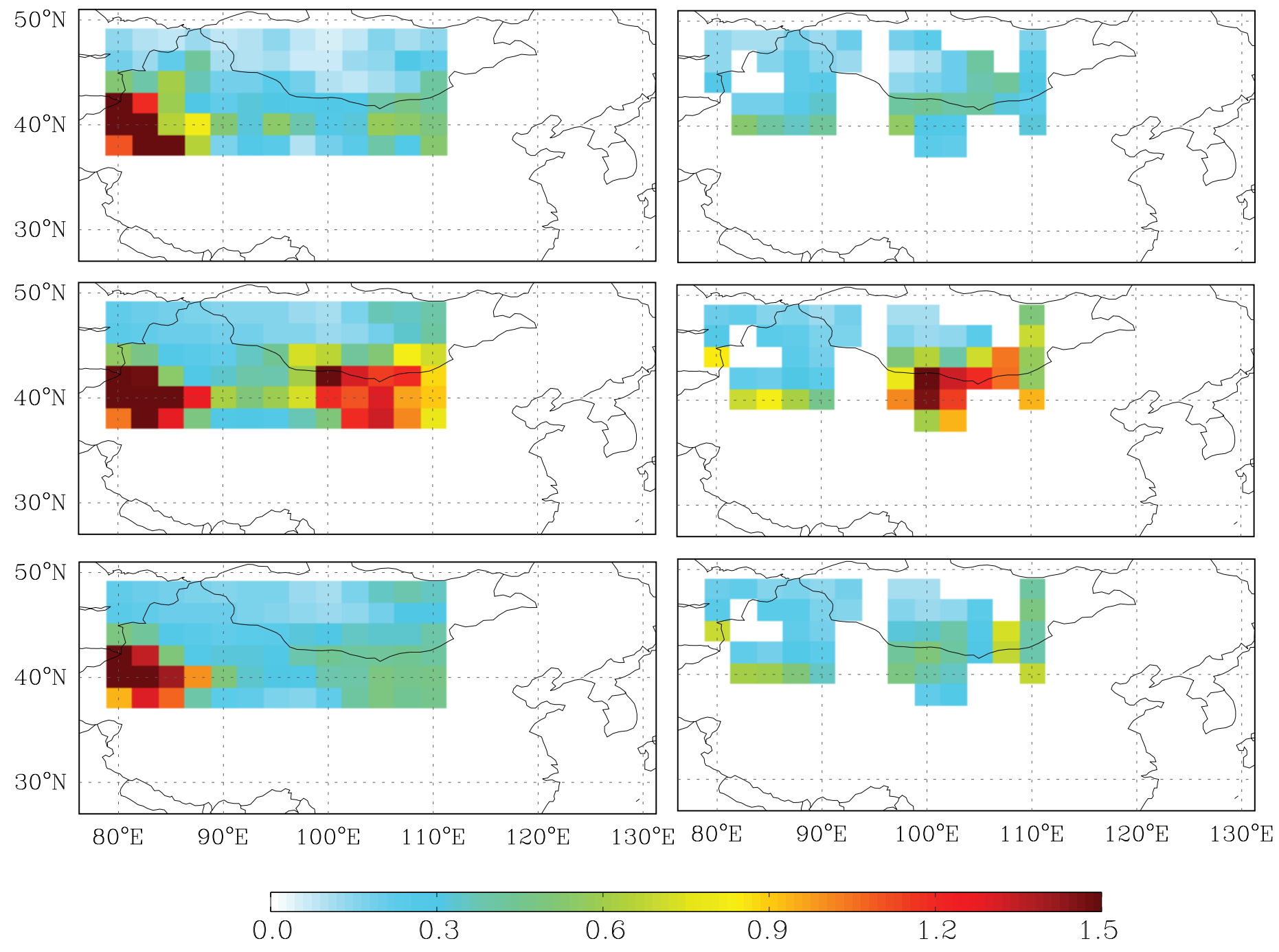